\title{
The Impacts of Enhancing Emotional Intelligence on the Development of Reading Skill
}

\author{
Mohammad Reza Ebrahimi \\ Corresponding author, Department of English Language, Bam Branch, Islamic Azad \\ University, Bam, Iran, rezaebrahimi2@yahoo.com

\section{Hooshang Khoshsima} \\ Assoc. Prof., Language Department, Chabahar Maritime University, Iran, \\ khoshsima@cmu.ac.ir

\section{Esmail Zare-Behtash} \\ Assoc. Prof., Language Department, Chabahar Maritime University, Iran, \\ behtash@cmu.ac.ir
}

Keywords: EFL learners, emotional intelligence, emotional intelligence development, intelligence quotient, reading skill

\section{INTRODUCTION}

Learning an international language (especially English language) has turned to a necessity in the lives of the public and the academicians. For some learners it is not a 
burden, but for some others it is a never-ending challenge. Aptitude difference (defined by Dornyei, 2006) involves the argument that the difficulty of language learning is different for different people. The difficulty arises from differences which are caused by various factors, including the intelligence of individuals. As Salehi, M., and Sadighi, F. (2012) claim, intelligence can modify the speed of language learning and also the quality of it. But is IQ ('intelligence quotient' which is a total score derived from several standardized tests designed to assess human intelligence) alone enough to account for success? The validity of IQ tests (Intelligence Quotient Tests) as the sole criterion for accounting for success was criticized in Educational settings and companies which used to employ individuals based on it for many years (e.g.: Riggio, Murphy, and Pirozzolo (2002)). Davis (2004) argues that along with IQ, there is another influential factor in success which is Emotional Intelligence; he states that IQ affords the 'floor' and Emotional Intelligence affords the 'ceiling' for success. Schmidt and Hunter (1981) claim that one fifth of success could be attributed to IQ and the rest is ascribed to Emotional Intelligence. Emotional Intelligence (EQ/I) is defined by Coleman A. (2008) in his dictionary of psychology as the capability of individuals to recognize their own emotions and those of others, discern between different feelings and label them appropriately, use emotional information to guide thinking and behaviour, and manage and/or adjust emotions to adapt to environments or achieve one's goal(s). To the surprise of most people, Goleman (2005) claims almost the same thing, stating that the lion's share of the causes of success could be ascribed to EQ, not IQ!

The root cause of the creation of the concept of EQ could be traced back to early $20^{\text {th }}$ century while Thorndike (1920) almost developed the concept to speak of being able to understand and manage others and to act intelligently; however, after half a century of not paying attention to the concept, Michael Beldoch (1964) and Leuner (1966) academically used the term Emotional Intelligence for the first time. This first use of "emotional intelligence" is attributed also to Wayne Payne's dissertation, A Study of Emotion: Developing Emotional Intelligence.

EQ has been defined by Schutte, et al. (1998) as the ability to recognize, understand, adjust, and harness emotions. EI can be explained as the ability to monitor one's own and other people's emotions, to discriminate between different emotions and label them appropriately and to use emotional information to guide thinking and behavior. Ebrahimi and Khoshsima, (2014, p. 148) described it as "the ability to know feelings and emotions within one and in others -be it verbalizable or not- and using it to control thinking and action to achieve success". Some researchers conceive higher emotional intelligence a cause of being more empathic and more socially adroit (Brackett and Katulak, 2006; Lopes, Salovey, Cot and Beers, 2005; Lopes, Brackett, Nezlek, Schutz, Sellin and Salovey, 2004). Research also has shown that individuals with higher levels of EI are showing increased career success ( Lopes, Kadis, Grewal, Gall and Salovey 2006). EI is also associated with successful leadership and effective performance (Kim, Yoo, Lee, \& Kim, 2012.

\section{EI and Language Learning}

Learning a language has turned to an indispensible part of the lives of at least academicians in the interdependent world. Among the influential factors on learning, 
cognitive factors and affective ones were found to be important in learning in general and thus it is clear that they are influential in language learning in particular. Yet, there is a need for more research on the role of emotions in learning as Goetz et. al., stated that "Despite burgeoning research interest in the role of affect in psychological development, emotions experienced in the academic domain has until recently remained a largely unexplored field of psychological research" $(2007$, p. 3). It was found that motivation is influenced by emotions and also choice of learning strategies (cognitive and metacognitive), and thus ultimate achievement are all influenced by emotions. Cherniss (2000) claimed that teaching programs which seek to develop EI in different areas could be used and then management, communication and empathy training, stress management and conflict resolution will be improved.

Language learning is emotionally driven; it is claimed by many researchers (e.g.: MacIntyre, MacKinnon, \& Clément, 2009; Dörnyei, 2005; Imai, 2010; López, 2011). Riemer (2003) argues that EQ skills improve learning potential of foreign language acquisition. Meng and Wang (2006) also argue that language learning could be facilitated by positive emotions and it also improves language performance. López (2011) asserts that cultivating emotions can assist solving demotivation formed by anger or fear which can jeopardize language acquisition. She maintains that evoking emotions increases self-esteem and empathy which significantly contributes to learners' attitudes and motivation and facilitate language learning. MacIntyre (2002, p.45) also stated that emotions "just might be the fundamental basis of motivation, one deserving far greater attention in the language learning domain". Two other influential factors on second language learning achievement are motivation for and attitudes towards second language (Hadfield \& Dörnyei, 2013; Dörnyei \& Kubanyiova, 2014).

Language learning is a process in which individuals informally test their own learning by memorizing each and every grammatical rule or new vocabulary. Language learners also test themselves by success in every conversation and encountering with foreigners; more importantly, they are being formally tested in learning language and TOEFL or IELTS scores are the prerequisite of enrollment in many universities in English speaking countries; thus, the importance of emotions increases. Goetz, Franzis P., Reinhard, and Nathan C. (2007, p. 4) stated that "Due to their impact on achievement outcomes, emotions experienced in testing situations are a particularly critical topic of investigation in modern, achievement-oriented societies". Being able to control or develop emotional practices should end in feelings of self-control (Lok \& Bishop, 1999). Goetz and colleagues further add that little is known about students' emotions which are experienced in academic settings (including their emotions during taking tests). The present study aims to contribute to reducing this research gap by investigating students' emotional experiences during learning a new language which is a very complex process and certainly deals with emotions.

\section{EI and Reading Skill}

Regarding success in learning in general, Parker, Summerfeldt, Hogan, \& Majeski (2004) proved that the highly successful learners achieved higher scores in comparison with the unsuccessful group on three out of the four subsets (and adaptability, intrapersonal ability, stress management) of EI. Pishghadam (2009) asserts that some 
methodologies particularly address emotional and psychological issues in SLA (e.g.: Suggestopedia), some of them were motivated by Krashen's claims (1981) affective filter in particular in the Monitor Model. Inspired by this claim some studies were done. For instance to determine whether EQ had any relationship with reading comprehension and structural ability of language learners Motallebzadeh (2009) did a study. 170 intermediate participants out of 250 EFL learners who took a language proficiency test (MELAB, 1997) were selected and took the self-report measure Bar-On Emotional Quotient Inventory (EQ-i, 1997). The findings showed that there was a strong relationship between EI and EFL learners' reading comprehension and structural ability except for two subscales of EI namely: social responsibility and empathy as interpersonal categories.

In another similar study, a positive relationship between language learning strategies and overall EQ was found by Aghasafari (2006). Majidi Dehkordi \& Shirani Bidabadi (2015) investigated the relationship between reading strategy use of Iranian EFL learners and their EI. The findings showed a greater degree in the use of cognitive and also meta-cognitive strategies by the high EI group and the reverse was observed for the low group.

Vahdat and Khavandgaran (2013) studied the link between reading comprehension of Iranian EFL learners (attending TOEFL classes) and their verbal/emotional intelligence and found a meaningful relationship between the two variables. Researchers have also found that the use of learning strategies in language classroom is an important factor in the success of EFL learners (Oxford, 1990). In the same line of inquiry, Abdolrezapour and Tavakoli (2012) examined the relationship between reading ability of Iranian EFL learners and EI. The learners in experimental group who were trained by a program based on Goleman's framework (containing short stories reading with highly emotional content) scored higher on a reading comprehension test.

\section{The Significance of the Study}

There is a continual call for educationalists to take responsibility for improving the emotional and social growth of learners due to a relationship between high EI and academic achievement, and the understanding that a productive education is entangled with emotional and social competencies (Liff, 2003). College mission statements are written to seek the cognitive and also non-cognitive training of learners; emphasizing the individual development and making the student ready to live outside of the school (Feldmann, Aper, \& Meredith, 2011). Some scholars enumerated the development of cognitive and social skills as one of the fruits of studying at university (Feldmann et al., 2011; Seal, Naumann, Scott, \& Royce-Davis, 2010). The majority of student development research is centralized on how they grow cognitively, despite the fact that how students make relationships, self-confidence, and the ability to communicate is exceptionally essential to the general visions and missions of higher education. Thus, the current study is significant inasmuch as teaching in university and before that, is aimed at the growth of the whole learner, cognitively and psychosocially.

Provided that it could be shown that EQ is significantly influencing Reading Skill, it seems necessary to pay more attention to that, for example teaching EQ might be 
required to be included in the language teaching syllabus. Regarding the huge amount of time and money which is being spent and invested on learning and teaching foreign languages, it seems to be a very redeeming job to find a shortcut. One of the ways for increasing the speed of learning seems to be dependent on dealing with emotions in an accurate way. The issue turns to a more significant one while one considers that English language is the major and almost the only medium of internationally sending and transferring knowledge, at least in Iran and also in some other countries. Using online articles in the internet, attending top universities, developing technology and industry and in brief every benefits which could be enumerated for learning English, could also be enumerated for the reasons of increasing the speed and quality of learning it, and that could be thought of as the significance of the current study. In a more idealistic view, provided that a learner finds EQ enhancement as a beneficial task, it could be generalized to other skills and knowledge; even if it could be instructed in different majors in universities. The current study is after offering additional evidence to observe the match or mismatch between theoretical assumptions and empirical demonstration of the relationship between EQ and Reading Skill.

The present investigation is most important insofar as it empirically explores the probable influence of EQ enhancement on the development of Reading skill in language learning among university students. Also, curriculum development based on focusing on EQ enhancement will be justifiable while it is based on research along with empirical investigations rather than sensationalistic claims. All in all, the current study was done to answer the following research question:

Research Question: Does emotional intelligence enhancement influence reading skill?

For the above-mentioned research question, the following hypothesis was posed:

Ho: Emotional Intelligence Enhancement does not influence Reading skill.

\section{METHOD}

'Quasi Experimental Study' design of the current study was put into practice as follows. Questionnaires were used in the study both at the beginning of the experiment and at the end of the educational year which was the period in which EQ was being taught.

\section{Participants}

The participants of the study were all studying at the same university (Gonabad University, Iran). Students who study at the same university in Iran, have almost the same level of proficiency in English as they are placed based on a national university entrance exam. However, for reaching a more accurate assessment of the proficiency, students have been carefully selected based on the scores of 'Interchange Placement Test' administered by the authors at the beginning of the project.

To ascertain that there were no outliers among the participants, 43 intermediate EFL learners were carefully chosen from among 56 EFL learners based on convenient sampling as access was not possible to EFL learners for one educational year in different universities. They were freshman who aged between 18 and 23 years. Out of 30 learners, 18 were females and 12 males in the experimental group. The control group was composed of 13 students ( 7 male and 6 female). The authors did not group the learners 
as they were grouped in different classes from before, thus, intact selection was done not random selection. Almost none of the students attended any conversation class except for regular English classes held in high school and junior high school, thus it could be safely claimed that the proficiency of the participants was not significantly different at the beginning of the project.

\section{Ethical Considerations}

To ensure the anonymity and also for the sake of reliability and validity of the answers given to the questionnaire, questions were coded numerically. The significance of the project was clarified for the students and the probable effects of the results on the progress in their future exams were explained. Thus, the subjects were eager to participate in the study and they verbally acknowledged their agreement. A number of the participants were randomly selected and interviewed to check the reliability of their responses after gathering the questionnaires, since one of the problems with studies based on the questionnaires is their susceptibility of gathering untruthful data.

\section{Data Measurement}

This study made use of summated instrument scale or in other words the Likert scale. A score from 0-5 was assigned to each EQ questionnaire's item, which means that they can be summed and then they can produce a total score (Coldwell \& Herbst, 2004). Higher total EQ scores indicate stronger emotional intelligence skills.

\section{Instruments}

The "Bar-On EI" test and a standard and an IELTS test were given to the students. BarOn devised a self-report Emotional Intelligence scale composed of 133-item for measuring. The emotional quotient inventory (EQ-I) offers an appraisal of EQ containing 5 major scales and 15 subscales. The Persian version of the test was utilized in the current research in order to achieve more reliable and valid results based on Iranian culture. Dehshiri (2003) claimed that the Persian translated version of the test is reliable and valid regarding Iranian culture. Estimated via Cronbach's alpha, the total reliability of the questionnaire was 0.82 ,

To measure Reading skill an IELTS test was given to the students before measuring EQ. Then EQ class started adjacent to their regular class, although the class was mostly focused on reading emotional topics. At the end of the semester, the same IELTS test was given to the students as post test to measure their progress in Reading skills and simultaneously their EQ was measured through the same questionnaire to examine whether their EQ has changed at all, or not.

\section{Data Collection}

State university of Gonabad, Khorasan-Razavi province was the place of the study, during two semesters of one educational year (2016-2017). Learners were firstly instructed on what was the project and the process of carrying it out. They were made familiar with the questionnaire (the Bar-On EQ test), and the activities they would do to develop their EI and the advantages of EI to make them more willing to participate in the study. 
Then 'Interchange Placement' test was given to make sure that the proficiency level of the students is almost the same and there would be no outliers. After the evaluation of the answers few students who were very weak or on the opposite extreme, very advanced, were eliminated from the study and intermediate students were selected to participate in an IELTS test in order to measure their ability in reading skill. The results of IELTS test which was administered as pre-test, almost confirmed the results of Interchange Placement test. Then students were given instruction on EQ, what it is and how we can make a change. Some sessions were assigned to making the learners familiar with emotional intelligence and then practice on that was started. The topics of reading were chosen based on emotional issues.

After Reading the texts which were mostly emotional ones, students were asked to discuss their feelings and experience inside the class and share their knowledge with the classmates. Hence, after working on emotions and writing, the same was happening for speaking skill. Some texts were assigned to the students to be studied in order to increase the knowledge of students on Emotional intelligence and teach them words with high emotional concepts. The reading texts were chosen based on the amount of emotional content they had and as a result, students could be familiar with many emotional words and expression to be better able to label their emotions and also understand them.

Simultaneously, the control group answered the same IELTS test as pretest and posttest in the same period of time. In order to increase the accuracy of the research, EQ questionnaires were filled by the participants in the control group both at the beginning of the semester and at the end. They also participated in the same Interchange Placement Test and IELTS test, both at the beginning and the end of the educational year. Thus, the study was done through enhancing EI in treatment group while measuring the progress in both EI and Reading Skill, and observing the progress of EI and Reading Skill in a similar classroom -the control group- in which no instruction on EI was taught. Both pre and post-tests of IELTS and were then rated by two raters in order to increase inter rater reliability of the scores. The average of the scores was used as the final score for each exam.

The materials were selectively chosen from a manual of teaching EQ to the leaders and some changes and adaptations were made to gear the manual to students who will be the leaders of their own classroom as teachers. The title of the manual is " 50 Activities for Developing Emotional Intelligence” written by Adele B. Lynn as the author describes the book and wrote that it is a collection of activities perfect for skill-building on selfawareness and control, empathy, social expertness, personal influence, mastery of vision and more.

\section{A Sample Lesson Plan of the Study}

A sample lesson plan extracted from the manual (P: 259) is offered in this section to clarify what was working on in the class and how EQ was being taught during the course of instruction.

\section{Inspiring Words}




\begin{tabular}{cl} 
EQ Target & \\
\hline & Self-Awareness and Control \\
\hline \multicolumn{1}{c}{ Empathy } \\
\hline $\boldsymbol{V}$ & Social Expertness \\
\hline
\end{tabular}

\section{Objectives}

- To help participants create words that inspire their peers and connect them to the teacher's vision

- To help participants recognize the power of words

- To elevate the significance of words as a tool for speakers to use for Inspiring listeners

Estimated Time: 40 minutes

Materials: Emotional Intelligence Exercise \#30

Risk/Difficulty: High

\section{Tips for the Trainer}

The purpose of this exercise is to challenge anyone who holds to the notion that "actions speak louder than words" to at least consider the inspiring quality of well-chosen words and the impact these words can have on followers. Also, this exercise will assist people in selecting inspiring words that articulate their vision to their listeners.

Words engage the heart and the imagination. The words the leader uses to communicate his or her mission/vision can transform the message from one that is boring and mundane to one that is meaningful and worthy. Consider the following examples:

\section{UNINSPIRING}

To give presentations

To produce comfortable chairs

To design stores

\section{INSPIRING}

To give moving presentations in a beautiful, comfortable nature and park-like setting where great learning is inspired.

To produce chairs that transform tired and achy bodies into refreshed souls that feel capable of conquering the world.

To design stores that irresistibly draw attention, pique curiosity, create the illusion of mystery, and feel luxurious to the eyes.

You may wish to have examples of the written word that have inspired followers to act. Of course, words must be backed by action. So, as the teacher, be careful not to overplay the importance of words over one's actions. Both are important to inspire followers to action. You should communicate that leaders must have both consistent actions and words in order to be truly inspiring.

\section{FINDINGS}

In order to analyze the relevant data in this experiment, the Statistical Package for Social Sciences (SPSS), version 22 was employed. The level of significance was set at 0.05. Table 1 reveals descriptive statistics obtained from the control and experimental groups in EQ test at pre-test. 
Table1

Descriptive Statistics for the Control and Experimental Groups' Performance on EQ Test (Pre-test)

\begin{tabular}{lllllll}
\hline & Group & $\mathrm{N}$ & Minimum & Maximum & Mean & Std. Deviation \\
\hline Pre-test (EQ) & Control & 13 & 317 & 377 & 450.61 & 55.44 \\
\hline & Experimental & 30 & 511 & 572 & 483.56 & 47.50 \\
\hline
\end{tabular}

To ensure the normality of the distribution of the two groups at pre-test, a KolmogorovSmirnov test was run. The results revealed that the distribution of scores was normal in each group at pre-test (Control: $\mathrm{N}=13$, Statistic $=.201, \mathrm{p}=.155$; Experimental: $\mathrm{N}=30$, Statistics $=.109, \mathrm{p}=.200)$. Therefore, the researcher decided to use parametric statistics. In doing so, to compare the mean scores of the two groups at the pre-test, an independent samples t-test was conducted. The results of independent samples t-test for the performance of the experimental and control groups at the pre-test of EQ revealed that there was no significant difference between the EQ mean scores of the two group at the beginning $(\mathrm{t}=-1.986, \mathrm{p}=.054)$.

Descriptive statistics obtained from the control and experimental groups for the reading skill at the beginning of the experiment is shown in Table 2.

Table 2

Descriptive Statistics for the Control and Experimental Groups' Performance on the Reading Test (Pre-test)

\begin{tabular}{lllllll}
\hline & Group & $\mathrm{N}$ & Minimum & Maximum & Mean & Std. Deviation \\
\hline $\begin{array}{l}\text { Pretest } \\
\text { (Reading) }\end{array}$ & Control & 13 & 3.75 & 6 & 4.67 & .54 \\
\cline { 2 - 7 } & Experimental & 30 & 3.25 & 6.25 & 4.45 & .79 \\
\hline
\end{tabular}

The results of Kolmogorov-Smirnov test revealed that the distribution of scores was not normal in the control group $(\mathrm{N}=13$, Statistics $=.240, \mathrm{p}=.039)$ and experimental group $(\mathrm{N}=30$, Statistics $=.208, \mathrm{p}=.002)$ at the pre-test.

Therefore, the researcher decided to use non-parametric statistics. In doing so, to compare the mean scores of the two groups at the pre-test, a Mann-Whitney Test was run. The results of Mann-Whitney Test for the performance of the experimental group (Mean Rank= 20.37) and control group (Mean Rank= 25.77) at the pre-test of Reading showed that there is no significant difference between the two groups in the scores of the reading at the beginning $(\mathrm{U}=146, \mathrm{p}>.05)$.

Descriptive statistics obtained from the control and experimental groups' reading gain scores is shown in Table 3.

Table 3

Descriptive Statistics for the Control and Experimental Groups' Gain Scores on the Reading Test

\begin{tabular}{lllllll}
\hline & Group & $\mathrm{N}$ & Minimum & Maximum & Mean & Std. Deviation \\
\hline Gain Scores & Control & 13 & -.5 & 1.25 & .4 & .45 \\
\cline { 2 - 7 } (Reading) & Experimental & 30 & -2.25 & 3.25 & .85 & 1.08 \\
\hline
\end{tabular}


The results of Kolmogorov-Smirnov test revealed that the distribution of gain scores was normal in the control group $(\mathrm{N}=13$, Statistic $=.185, \mathrm{p}=.200)$; however, it was not normal in the experimental group $(\mathrm{N}=30$, Statistic $=.178, \mathrm{p}=.016)$. The results of Mann-Whitney Test for the performance of the experimental (Mean Rank= 16.19) and control (Mean Rank= 24.52) groups for the reading gain scores showed that there was a significant difference two groups in the gain scores of reading $(U=119.5, \mathrm{p}<.05)$.

Table 4 shows the descriptive statistics for the gain scores in EQ test.

Table 4

Descriptive Statistics for the Control and Experimental Groups' Gain Scores on EQ Test

\begin{tabular}{lllllll}
\hline & Group & $\mathrm{N}$ & Minimum & Maximum & Mean & Std. Deviation \\
\hline Gain Scores & Control & 13 & -23 & 39 & 4.69 & 16.73 \\
\cline { 2 - 7 } (EQ) & Experimental & 30 & -35 & 76 & 23.3 & 22.36 \\
\hline
\end{tabular}

The results of Kolmogorov-Smirnov test revealed that the distribution of the gain scores were normal in each group both in control group $(\mathrm{N}=13$, Statistic $=.209, \mathrm{p}=.125)$ and in experimental group $(\mathrm{N}=30$, Statistic $=.128, \mathrm{p}=.200)$. The results of independent sample t-test for the experimental and control groups' gain scores of EQ showed that there is a significant difference between the two groups regarding the mean scores of the gain scores $(\mathrm{t}=-2.68, \mathrm{p}<.05)$.

\section{DISCUSSION}

The effect of EQ enhancement on the progress of reading ability was the aim of the current study. This experimental study proved that EQ increased significantly along with reading skill. The results were in agreement with the results of some investigations like what Goleman (1995), Mayer et al. (1999), Jaeger (2003) found. They showed that EQ is not fixed and it could be developed contrary to IQ. EQ was taught for one educational year course in the current investigation and the findings revealed that while in treatment group the EQ of the subjects was significantly enhanced, in control group no significant change was observed. The results of the current study confirmed the findings of Bar-On (1997) who also suggested that EQ keeps up growing with age and maturity and therefore can be enhanced. Sala (2000) taught EQ in a training program and faced similar findings with what the researchers of the current study have found. A four-weekcourse of instructions by Slaski and Cartwright (2002) also caused a significant change in the EQ of experimental group which is in the same line with what happened for the present study. Some longitudinal research like those of Vaillant (2000) and also Kagan (1998) were confirmed by the present research.

Considering academic success Salahi (1998), Aghasafari (2006), and Fahim and Pishghadam (2007) also found EQ to be linked with academic success which was confirmed in the current study. Also regarding the progress in reading skill Vahdat and Khavandgaran (2013) revealed a significant positive relationship between EI and reading ability, which was confirmed by the current research. The results of the study are in line with the findings of Abdolrezapour and Tavakoli (2012) on the relationship between reading and EI. Majidi Dehkordi \& Shirani Bidabadi (2015) encountered the same results with the findings of the present research. The findings prove that the above 
mentioned researchers along with the researchers of the current study made an informed guess based on the influence of emotional intelligence influence on success in general and success in language learning and its components in particular. The researchers then taught EQ, and it was observed that after one year, EQ enhanced and also Reading skill was developed in a much more better way. If educational systems, stakeholders, syllabus designers, include the element of emotion and emotional intelligence in the syllabi, and consequently make learners conscious of their emotions and the role played by emotions in success in general and in language learning in particular, they can expect the same results as the researchers encountered that is a more promising future in their educational outcomes.

\section{CONCLUSION}

Affective factors were found to be influential in learning after scientists found a role for cognitive factors in the process of learning. Thus, emotional regulation and control could be probably related to learning a language as both 'learning' and 'affections' are involved. The authors of the present research assumed that developing EQ can cause progress in language in general. Subjects were instructed on EQ and after one year the progress in Reading Skill along with EQ was observed.

EQ was needed to be taught for one educational year; the probability for having access to subjects with the same level of proficiency in such a long period of time did not exist. Naturally in such circumstances, sampling procedure has to be done based on 'Intact Group' selection not random selection. This is a limitation of the present research; in order to reach more generalizable results, replications of the study shall consider this limitation.

EQ seems to be yet neglected as there is a lot of theoretical research and a little empirical experience, let alone applying the results in the syllabi. After ensuring of the generalizability of the results of the current study by replicating it in various contexts with different participants, syllabus designers might reconsider the content of the syllabi. EQ can be involved in new syllabi, regarding its effect on education. Furthermore, it seems to be a redeeming job to inform educators of the versatility of EQ, and thus making them informed of the role of EQ in the success of education. Even if no reconsideration in syllabi would be approved, at least workshops on EQ for teachers or some in-service instructions seem to be productive.

\section{REFERENCES}

Abdolrezapour, P. \& Tavakoli, M. (2012). The relationship between emotional intelligence and EFL learners' achievement in reading comprehension. Innovation in $\begin{array}{llll}\text { Language Learning } \quad \text { Teaching, } & \text { 6(1), }\end{array}$ http://dx.doi.org/10.1080/17501229.2010.550686

Aghasafari, M. (2006). On the relationship between emotional intelligence and language learning strategies. Unpublished master's thesis, Allameh Tabataba'i University, Iran. 
Bar-On, R. (1997). Bar-On Emotional Quotient Inventory (EQ-I): Technical Manual. Toronto, Canada: Multi-Health Systems.

Beldoch, M. (1964). Sensitivity to expression of emotional meaning in three modes of communication, in J. R. Davitz et al., The Communication of Emotional Meaning, McGraw-Hill, pp. 31-42

Brackett M. A., Katulak N.A., (2006). Emotional intelligence in the classroom: skillbased training for teachers and students. In Applying Emotional Intelligence: A Practitioner's Guide, ed. JCiarrochi, JD Mayer, pp. 1-27. New York: Psychol. Press. Taylor \& Francis.

Cherniss, C. (2000). Social and emotional competence in the workplace. In R. Bar-On \& J. Parker (Ed's.), The Handbook of Emotional Intelligence. San Francisco: Jossey-Bass.

Coldwell, D. \& Herbst, F. (2004). Business Research: Juta and Co Ltd.

Coleman, A. (2008). A Dictionary of Psychology (3 ed.). Oxford University Press. ISBN 9780199534067

Davis, M. (2004). Test Your EQ. London: Piatkus

Dehshiri, R. (2003). The Reliability and validity of EQ-I in Iran's context. Unpublished master's thesis, Allame Tabataba'i University, Tehran, Iran.

Dornyei, Z. (2006). Individual differences in second language acquisition. AILA Review, 19(1), 42-68.

Dörnyei, Z., \& Kubanyiova, M. (2014). Motivating learners, motivating teachers: Building vision in the language classroom. Cambridge, UK: Cambridge University Press.

Ebrahimi, M. R., Khoshsim, H. (2014). On the Association(s) between Test Anxiety and Emotional Intelligence, Considering Demographic Information; A Case of Iranian EFL University Students. International Journal on Studies in English Language and Literature, 2(7), 147-157.

Fahim, M., \& Pishghadam, R. (2007). On the role of emotional, psychometric, and verbal intelligences in the academic achievement of university students majoring in English language. Asian EFL Journal, 9, 240-253.

Feldmann, M., Aper, J. P., \& Meredith, S. T. (2011). Co-curricular assessment scale development. The Journal of General Education, 60,16-42.

Goetz, T. (2004). Emotionales Erleben und selbstreguliertes Lernen bei Schülern im Fach Mathematik [Students' emotions and self-regulated learning in mathematics]. Muenchen: Utz.

Goetz, T., Preckel, F., Pekrun, R., \& Nathan C. Hall. (2007). Emotional experiences during test taking: Does cognitive ability make a difference? Learning and Individual Differences, 17, 3 - 16.

Goleman, D. (1995). Emotional intelligence: why it can matter more than IQ. London: Bloomsbury. 
Hadfield, J., \& Dörnyei, Z. (2013). Motivating learning. Harlow, UK: Longman.

Imai, Y. (2010). Emotions in SLA: New insights from collaborative learning for an EFL classroom. Modern Language Journal, 94(2), 278-292. http://doi.org/cqwt6x In R. J. Sternberg (Ed.), The handbook of intelligence (pp. 396-420). New York: Cambridge University Press.

Jaeger, A. J. (2003). Job competencies and the curriculum: An inquiry into emotional intelligence in graduate professional education. Research in Higher Education, 44(6), 615-639. doi:10.1023/A:1026119724265.

Kagan, J. (1998) Galen"s prophecy. Boulder, CO: Westview Press.

Kim, T., Yoo, J. J.-E., Lee, G., \& Kim, J. (2012). Emotional intelligence and emotional labor acting strategies among frontline hotel employees. International Journal of Contemporary Hospitality Management, 24, 1029-1046.

Leuner, B (1966). Emotional intelligence and emancipation. Praxis der Kinderpsychologie und Kinderpsychiatrie. 15, 193-203.

Liff, S. B. (2003). Social and emotional intelligence: Applications for developmental education. Journal of Developmental Education, 26(3), 28-32.

Lok, C, \& Bishop, G. D. (1999). Emotion control, stress, and health. Psychology and Health, 14, 813-827.

López, M. M. (2011). The motivational properties of emotions in foreign language learning. Colombian Applied Linguistics Journal, 13(2), 43-57.

Lopes P. N., Brackett M. A., Nezlek J. B., Schutz A., Sellin I., \& Salovey P. (2004). Emotional intelligence and social interaction. Personal. Soc. Psychol. Bull. 30,1018-34.

Lopes, P. N., Grewal, D., Kadis, J., Gall, M. \& Salovey P. (2006). Evidence that emotional intelligence is related to job performance and affect and attitudes at work, Psichothemia, 18(1),132-138.

Lopes P. N., Salovey P., Cot^e S, \& Beers M. (2005). Emotion regulation abilities and the quality of social interaction. Emotion, 5,113-18.

MacIntyre, P. (2002). Motivation, anxiety and emotion in second language acquisition. In P. Robinson (Ed.), Individual differences and instructed language learning (pp. 4568). Amsterdam: John Benjamins Publishing.

MacIntyre, P. D., Mackinnon, S. P., \& Clément, R. (2009). The baby, the bathwater, and the future of language learning motivation research. In Z. Dörnyei \& E. Ushioda (Eds.), Motivation, language identity and the L2 self (pp. 43-65). Bristol, UK: Multilingual Matters.

MajidiDehkordi, B., \& ShiraniBidabadi, F. (2015). Relationship between Iranian EFL learners' reading strategy use and emotional intelligence. International Journal of Foreign Language Teaching and Research, 3 (9), 36-43.

Mayer, J. D., Caruso, D. R., \& Salovey, P. (1999). Emotional Intelligence meets traditional standards for an intelligence, Intelligence, 27, 267-298. 
Motallebzadeh, K. (2009). The relationship between the emotional intelligence of Iranian EFL learners and their reading comprehension and structural ability. Journal of Teaching English as a Foreign Language and Literature, 1(4), 39-55.

Oxford, R. L. (1990). Language Learning Strategies: What Every Teacher Should Know. Boston: Heinle \& Heinle.

Parker, J. D. A., Summerfeldt, L. J., Hogan, M. J., \& Majeski, S. (2004). Emotional intelligence and academic success: Examining the transition from high school to university. Personality and Individual Differences, 36, 163-172.

Pishghadam, R. (2009). A quantitative analysis of the relationship between emotional intelligence and foreign language learning. ElectronicJournal of Foreign Language Teaching, 6(1), 31-41.

Pishghadam, R. (2009). Emotional and verbal intelligences in language learning. Iranian Journal of Language Studies, 3(1), 43-64.

Riggio, R. E., Murphy, S. E., \& Pirozzolo, F. J. (Eds.). (2002). Multiple Intelligence's and Leadership. Mahwah, N.J.: Lawrence Earlbaum Associates.

Sala, F. (2002) Do programs designed to increase emotional intelligence at work -work? EI program evaluation, Consortium for Research on Emotional Intelligence in Organizations. $\quad$ Accessed 17/5/12 http://www.eiconsortium.org/pdf/mastering_emotional_intelligence_program_eval.pdf

Salahi, G. (1998). The effect of intelligence on the performance of EST students on reading comprehension. Unpublished master's thesis, University of Science and Technology, Tehran, Iran.

Salehi, M., Sadighi, F. (2012). The Relationship between Intelligence and Foreign Language Learning, and the Role of Practice. Journal of Language, Culture, and Translation, 1(1), 33-48.

Schutte, N. S., Malouff, J. M., Hall, L. E., Haggerty, D. J., Cooper, J. T., Golden, C. J., \& Dornheim, L. (1998). Development and validation of a measure of emotional intelligence. Personality and Individual Differences, 25, 2, 167-177. doi:10.1016/S0191-8869(98)00001-4

Seal, C. R., Naumann, S. E., Scott, A. N., \& Royce-Davis, J. (2010). Social emotional development: A new model of student learning in higher education. Research in Higher Education Journal, 10, 1-13.

Slaski, M. \& Cartwright, S. (2002) Health, performance and emotional intelligence: An exploratory study of retail managers. Stress and Health, 18(2), 63-68.

Thorndike, E.L. (1920). Intelligence and its uses. Harper's Magazine, 140, 227-235.

Vahdat, S., Khavandgaran, S. M. (2013). The Relationship between Verbal and Emotional Intelligences and Iranian. The Iranian EFL Journal, 50, 380.

Vaillant, C. E. (2000) Adaptive mental mechanisms: Their role in a positive psychology, American Psychologist, 55, 89-98. 